\title{
Research on College English Blended Learning Mode under the "Internet+" Environment
}

\author{
Dehua Guan ${ }^{\mathrm{a}}$ and Jie $\operatorname{Tan}^{\mathrm{b}^{*}}$ \\ Wuhan University of Science and Technology, Hubei, China \\ a529859058@qq.com, b646340376@qq.com \\ *The corresponding author
}

Keywords: Internet+; Blended learning; English teaching; Interaction

\begin{abstract}
This paper explores the blended learning mode of college English with the "Internet+" environment as background. Blended Learning reduces the cost of learning, which is convenient for the interaction and communication between teachers and students. In this paper, we discuss the technology and strategy of Blended Learning in college English based on the "Internet+" environment, which aims to resolve the paradox between limited contents of classroom teaching and students' personalized learning requirements, to stimulate students' learning interests, and to enhance the quality of college English teaching. This innovative teaching mode is more effective in stimulating students' learning motivation and improving their pragmatic competence.
\end{abstract}

\section{Introduction}

Information technology has begun to play a revolutionary impact on the creation, dissemination, access, management and utilization of knowledge. [1]The combination of Internet and traditional teaching will also be an important long-term goal of the development of higher education. The new teaching mode of "Internet+ teaching", emphasis more on the characteristics of the interaction with students as the center of the independent personality in the process of learning, pay more attention to cooperative learning among members of learning, and between students and teachers. With the advance of information technology in education, traditional college English teaching mode is challenged, and can no longer culture students' English comprehensive application ability as well as before. Thus cause the decline of the quality of instruction, and cannot adapt to the change of society and language.

In the "Internet+" environment, by the employment of blended learning, we can combine the advantages of traditional teaching and E-learning; get rid of the previous habit of relying on teachers and complete obedient to teachers. Blended learning encourages students to carry out English learning according to their own specific circumstances by using the network. In this way, we can achieve the transformation of teacher-centered teaching mode to student-centered teaching mode, and effectively broaden students' English learning beyond the classroom and without teachers. Thus, teachers only need to inspire and guide face-to-face on students' learning difficulties in the learning process, and strengthen the focus of the course, so as to change their roles as designers, observers, listeners, guides, evaluators, consultants and mentors of the students in their study. Meanwhile, students should construct their knowledge actively with the assist of teachers. The design of blended learning mode is to facilitate the guidance and monitoring of the teaching. In addition to blend on-line and off-line learning, we can also blend specific learning materials and flexible learning materials, self-regulated learning and collaborative learning, structured learning and unstructured learning, thus to effectively enhance the quality of college English teaching.[2] 


\section{Concept of Blended Learning}

On blended learning, researchers have varieties of different understanding. Blended learning refers to the integrated use of different learning theories, different techniques and methods as well as different application ways to implement a strategy of teaching.[3] Through the organic integration of two typical forms of teaching: face-to-face learning and E-learning, blended learning has become the main trend of the current teaching mode. It aims at integrating the advantages of face-to-face learning and E-learning, using a combination of teacher-based teaching collective teaching form, team-based teaching form based on the concept of "cooperation" and the autonomous learning-based teaching method.[4] One of the most simple understanding is that blended learning is an advanced planning learning form which combined E-learning. face-to-face learning and self-regulated learning. It is a combination of a variety of learning styles and different from a single study way.

In Maegatet Driscoll's opinion, blended learning refers to four different concept: combining or blending a variety of network technologies (such as real-time virtual classroom, self-regulated learning, writing learning, and streaming video, audio and text) to achieve teaching goals; Combining a variety of teaching methods (such as constructivism, behaviorism, cognitive), making use or not making use of instructional technology to produce the best learning results; Combining any kind of teaching technique with teachers' face-to-face instruction; Combining or blending the teaching techniques and practical tasks so as to make learning and work coordinated.[5]Blended learning process emphasizes the combination of teacher-led and student' subjective statue, the nature of the research is to study the channels of information transmission, the key is selection and combination of the media.

\section{Characters of Blended Learning}

Traditional English teaching is mainly based on the students' autonomous learning, lacking of interactive teaching and learning, unable to communicate and cooperate with team members, as we can see in Table 1. So it is hard to promote the cultivation of language learners' pragmatic competence.

Table 1 Comparison of Traditional Learning and Blended Learning

\begin{tabular}{|l|l|l|}
\hline & Traditional Learning & Blended Learning \\
\hline Teacher & Initiator, administrator & Conductor, promoter \\
\hline Student & Passive receive & Active researcher \\
\hline Technology applied & Content presentation & $\begin{array}{l}\text { self-regulated learning, Internet } \\
\text { interaction }\end{array}$ \\
\hline Evaluation method & Traditional paper test & Multi-dimension, multimode \\
\hline
\end{tabular}

Blended learning mode under the "Internet+" Environment to some extent compensate for the insufficiency. It has the following unique advantages:

Realize Mobile Teaching Anytime and Anywhere. Students and teachers are free to negotiate the time, as long as there is Internet coverage where you can enter the virtual classroom to take out the teaching activities through mobile devices.

Fulfill Personalized Teaching Demand. As it is Learner-centered, it can enhance cooperation and communication between students, promote interaction between teachers and students. Through proper guidance and real-time evaluation, students are encouraged to use the target language in communication, thus to improve their pragmatic competence.

Flexible and Diverse Learning Method and Teaching Content. Blended Learning offer language learners a variety of input and output mechanism. Learners are willing to participate in the interactive 
process of teaching, increasing the chance to practice the language. Learning will be more effective in an interactive learning environment.

Control Teaching Pace and Schedule. According to learner's learning feedback, teachers can be relatively freely to control the speed and progress of teaching, and adjust teaching difficulty and speed in time.

\section{Design of College English Blended Learning Mode}

Language learning focuses on the training of basic skills, such as listening, speaking, reading, writing and translation, as well as improving students' ability of cross-cultural communication. [6]With the support of Internet technology and information technology, students can enhanced their basic language skills and carry out student-student interaction and teacher-student interaction through the Internet platform and finally show what they have learned in the classroom (or through Internet). Huang also believes that blended learning consists of four key aspects: course leaders, event organization, learning support and teaching evaluation.[4]Synthesizing blended learning at home and abroad, as well as Internet technology and foreign language curriculum integration mode, we propose the college English blended learning mode as three steps: self-regulated learning, Internet interaction, Classroom teaching.

Set Teaching Goal. In order to make teachers are no longer just the mouthpieces of knowledge and students are no longer the collectors of knowledge, but the carrier of meaningful and innovative culture, we need to set innovative internally and externally college learning environment. On the external environment, providing enough information to select, so as to stimulate students' interest and confidence in the professional field generated by understanding. Society and college are obliged to ensure the smooth flow of education right and humanization.[7]Informing students of the teaching content and goal, and the corresponding evaluation criteria explicitly is the first step to achieve the goal of teaching, which can help students make clear of the learning target. It will be better to combine instructional design with the textbook and give real events as examples, so that students can make sense of their practical value.

Design Learning Environment. Learning environment design of college English blended learning is essential, which including autonomous learning environment based on networks, collaborative learning environment and face-to-face classroom teaching environment.[8] Only by combining the three factors together, can we promote students' English learning. Under the "Internet + " environment, we do a preliminary design of the learning environment relying on independent learning centers, Renren and other social network sites, QQ, Wechat and other communication software, in order to providing navigation for the learners to carry out blended learning.

Design Teaching Process. First stage, learners study the language point of each unit through the Internet platform. In this way, they have a general idea of the text content. Teachers may ask students make further thinking on some issues and require them to search for information (at least through the library and Internet) then have a group debate. Second stage, students complete Internet homework, after-school exercise and unit testing. Teachers can also get involved in this stage through the Internet to help students organize the material and provide students with assistance. [9]After the first and second stage, learners are supposed to accept the face to face learning in classroom. In this stage, teachers will check students' self-regulated learning and collaborative learning, sort out important language points and analysis the structure and writing techniques of the text. Meanwhile, teachers can organize class debating activities. Classroom activity is also a feedback of students' independent learning. Students are the main part of classroom activities. Through classroom activities, students have a chance to present what they have learned and interact with teacher and other students. To a large extent, it can stimulate students' interests in learning English. Teachers should promptly give feedback of students' learning in face-to-face teaching stage. 
The above example of design is only part of the regular instructional design. However, instructional design is a systematic project. Teachers should start detailed work from the aspect of teaching environment, teaching objects, teaching contents, evaluation methods and so on [10] In the teaching process, students should not only learn the language point in the textbook, but also have collaborative learning in the form of group study. When giving students the task, teachers should make sure that the task of learning is clear and inform the students of intended teaching target. Teaches should accurately grasp the difficulty of the task. If the students' English level is quite low, while the teaching task is too difficult, it may lessen students' learning enthusiasm, which will make the result at cross purpose.

\section{Summary}

A major feature of the blended learning approach is the use of Internet. Currently, "Internet+" is quite popular in many fields. Apart from the traditional teaching methods, teachers can also bring "Internet+" in their teaching. Make full use of multimedia to arouse students' interests, thus to achieve better teaching effect. Through the blended learning method, that is, self-regulated learning in the first stage, Internet interaction in the second stage, and face-to-face teaching in the third stage, students can have a better understanding of language points and enhance language application skills. That is the purpose of our teaching.

\section{References}

[1] C. D. Dziuban, J. L. Hartman, and P. D. Moskal: Blended learning. Education Center for Applied Research (Oxford University Press, Britain 2005), p.135-138.

[2] F. L. Wang, J. Fong and R. C. Kwan. Information Science Reference (New York, December 12-14, 2010). Vol. 1, p. 86.

[3] H. R. Huang: Theory of Course Design based on Blended Learning, Vol. 1 (2009), p.42. (In Chinese)

[4] M. K. 1 Kabilan, N. A. and M. J. Z. Abidin: Facebook: An Online Environment for Learning of English in Institutions of Higher Education, Vol. 6 (2010), p.179-187.

[5] Z. Du, X. Xiao: Research on Interactive Online Learning system for Autonomous Learning, Vol. 6(2015), p.441. (In Chinese)

[6] W. Ma, X. P. Zhang: Research and Practice of College English Blended Learning, Vol. 5(2011), p.63. (In Chinese)

[7] J. Bergmann, A. Sams: Flip Your Classroom (ISTE \& ASCD, USA 2012), p.332.

[8] T. Anderson, J. Shattuck: Design-Based Research A Decade of Progress in Education Research [J]. Education Researcher, Vol. 4(2012), p.112.

[9] C. Y. Lin: Instructional theory for using a class wiki to collaborative learning in higher education (Ph.D., Indiana University, China 2013), p.55.

[10]T. C. Reeves: Design research from a technology perspective, Vol. 1(2006), p.79. 